4. Lysenko, O. (2000). Musical performance and the problem of his systematic study. Scientific Herald. Musicology: from the XX century to the XXI century (Issue 7), (pp. 162-171) [in Ukrainian].

5. Sumarokova, V. (2004). Performing school as an object of research: to define the concept. Scientific herald of National P. I. Tchaikovsky Academy of Music. (Issue. 40/10), (pp. 180-190) [in Ukrainian].

6. Kholopov, Yu. (1982). Musical and theoretical systems: The program for musical higher education institutions. in No. No. 2207, 2208 «Composition», «Musicology» [in Russian].

Стаття надійциа до редакції 08.06.2016

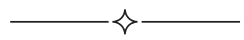

УДК 78.01/.071.2/.072.2+782.1

УХуйминь, соискатель кафедры теории музыки и композиции

ОНМА им. А. В. Неждановой

odma_n@ukr.net

\title{
ПСИХОЛОГИЧЕСКИЕ ПРЕДПОСЫЛКИ И УСЛОВИЯ ОПЕРНОЙ ВОКАЛЬНО-ИНТОНАЦИОННОЙ ИНТЕРПРЕТАЦИИ
}

\begin{abstract}
Цель работы - обосновать необходимость привлечения теории и методических принципов психологического театра в опероведение, раскрыть предпосылки и пути использования системы К. Станиславского в оперном творчестве, в совершенствовании оперной драматургии. Методология исследования предполагает синтез театроведческого $и$ музыковедческого подхода, дискурс-анализа применительно к учению К. Станиславского и В. Немировича-Данченко и психологии искусства. Научная новизна статьи состоит в развитии и расширении психологического подхода к оперной вокально-интонационной интерпретации как $\kappa$ артистической музыкально-театральной деятельности, в углублении со стороны опероведения представления о психологическом театре как особом художественно-творческом феномене. Выводы работы позволяют определять основные интерпретативные задачи режиссера, дирижера и певца-артиста, организующих оперную постановку, обнаруживать их специфику и художественно-смысловое единство.
\end{abstract}

Ключевые слова: психологический театр, система К. Станиславского, певец-артист, интерпретация, опероведение, оперное смыслообразование, оперное образно-сиеническое выражение. 
Wu Huimin, applicant of Department of history of music and musical ethnography, ONMA named after A. V. Nezhdanova

Psychological prerequisites and conditions of opera vocal-intonational interpretation

The work purpose - to prove need of attraction of the theory and the methodical principles of psychological theater in an operalogy, to open prerequisites and ways of use of system of $K$. Stanislavsky in opera creativity, in improvement of opera dramatic art. The methodology of a research assumes synthesis of theaterologycal and musicological approach, a discourse-analysis in relation to K. Stanislavsky and V. Nemirovich-Danchenko's doctrine and psychology of art. The scientific novelty of article consists in development and expansion of psychological approach to opera vocal-intonational interpretation as to artistic musical and theatrical activity, in deepening from an operalogy side of idea of psychological theater as a special art and creative phenomenon. Conclusions of work allow to define the main interpretive objectives of the director, conductor and singer-actor, organizing opera statement, to find their specifics and art and semantic unity.

Keywords: psychological theater, K. Stanislavsky's system, singer-actor, interpretation, operalogy, opera semantic formation, opera figurative and scenic expression.

У Хуймінь, здобувач кафедри історії музики та музичної етнографії ОНМА імені А. В. Нежданової

Психологічні передумови і умови оперної вокально-інтонаційної інmepnpeтаціï

Мета роботи - обгрунтувати необхідність залучення теорії $і$ методичних принципів психологічного театру в оперознавство, розкрити передумови та шляхи використання системи К. Станіславського в оперній творчості, в удосконаленні оперної драматургії. Методологія дослідження передбачає синтез театрознавчого і музикознавчого підходу, дискурс-аналізу стосовно до навчання К. Станіславського і В. Немировича-Данченка і психології мистецтва. Наукова новизна статті полягає в розвитку і розширенні психологічного підходу до оперної вокально-інтонаційної інтерпретації як до артистичної музично-театральної дiяльності, в поглибленні з боку озерознавства уявлення про психологічний театр як особливий художньо-творчий феномен. Висновки роботи дозволяють визначати основні інтерпретативні завдання режисера, диригента і співака-артиста, які організовують оперну постановку, виявляти їх специфіку і художньо-смислову єдність.

Ключові слова: психологічний театр, система К. Станіславського, співак-артист, інтерпретація, оперознавство, оперне смислоутворення, оперне образно-сиенічне вираження. 
Актуальность работы мотивирована необходимостью выделять и изучать те имена и творческие теории, которые способствовали развитию оперного исполнительства, приобретали кульминационное методическое положение, знаменуя достижение вершины «оперного смыслообразования» - и в его музыкально-интонационном, и в его целостном образно-сценическом выражении. Среди них и имена великих театральных режиссеров, обусловивших магистральные направления развития театрального искусства, повлиявших не только на его драматические, но и на музыкальные, в том числе оперные, формы.

«Психологический театр» - одно из эстетических направлений театрального искусства, возникшее в XVIII веке и получившее дальнейшее развитие в период начального становления режиссерского театра в XIX веке (завершающей фазе). Данное понятие часто употребляется в качестве синонима понятия реалистического театра и указывает на особое стремление к подлинности, к «правде жизни», следовательно, и к «правде переживания».

Осознание психологического театра как эстетической системы произошло на рубеже XIX-XX веков. Основную роль в этом сыграли два фактора. Во-первых, это развитие эстетических направлений натурализма и реализма, ставивших своей задачей достижение максимального правдоподобия. Конечно, реалистические элементы присутствовали и раньше. Так, драматургия А. Островского почти целиком базируется на реалистическом воспроизведении действительности. М. Щепкин, по словам А. Герцена, первым стал «не-театрален на театре», тем самым заложив основы русской психологической школы актерской игры. Однако формирование последовательной эстетической системы реалистического театра стало возможным лишь благодаря второму фактору, возникшему на рубеже XIX-XX веков и преобразовавшему все сценическое искусство. Речь идет о возникновении и становлении новой театральной профессии - peжиссера, вместе с которым возникает и системное представление о театральной постановке, а общий и обобщающий «взгляд» режиссера на спектакль открывает перед театром новые возможности в творчески-психологическом направлении.

Примечательно, что К. Станиславский подчеркивал универсальность законов не только театрального искусства, но и искусства вообще: «Законы истинного творчества, как и органические элементы его не составляют специфического стандарта, годного для одной на- 
ции, одной эпохи. Они общечеловечны, а потому годны каждому художнику во всех областях искусства. Они одинаковы для всех людей артистического склада.

Если артист постиг их и умеет в них жить на сцене, они приводят всегда к одному и тому же результату: своими внутренними представлениями, целой лентой собственных образов, живых и ярких, артист заражает своего партнера - а через него и зрителя, привлекает его обостренное внимание к своим сценическим действиям и заставляет его видеть события так, как он сам их видит.

Если весь коллектив артистов, участников спектакля, сумел жить в нем цельно и верно, в полном сосредоточенном внимании, увлекаясь жизнью людей сцены и не выбиваясь из нее, как из сценической правды, то зрители отвечают им своим вниманием, втягиваются в сценическую жизнь артистов, видя перед собой живых людей сцены, разделяют их действия, смеются и плачут над их сценическими радостями и горестями, боясь пропустить что-либо в этой воображаемой жизни и веря ее правде.

Подавая публике зрительного зала такой спектакль, артист выполняет великую воспитательную задачу театра: завлечь зрителя в сотворчество артиста сцены. И зритель непременно унесет из театра великую идею автора. Она будет беспокоить и заставлять стремиться к лучшей жизни в действительности» [1, 12-13].

Цель данной статьи - обосновать необходимость привлечения теории и методических принципов психологического театра в опероведение, раскрыть предпосылки и пути использования системы К. Станиславского в оперном творчестве, в совершенствовании оперной драматургии.

Основное содержание статьи. С именем К. Станиславского, а также В. Немировича-Данченко, основателей Московского Художественного театра, неразрывно связано само понятие «психологического театра», его рождение и расцвет. В теоретических и практических позициях Станиславского сжато выражены цели и задачи актера и театрального коллектива, а также высокая миссия театрального искусства. Принципы работы актера над ролью, над собой, принципы организации единой творческой жизни коллектива театра, которые открыли и систематизировали основатели МХАТа, стали универсальными законами психологического театра. «Система» Станиславского возникла и утвердилась, прежде всего, на почве русской демократической театральной культуре. История ее создания неотделима от 
творческого пути МХАТа, поскольку она складывалась в процессе борьбы за коренное обновление сценического искусства современников. В стенах МХАТа и его студий «система» проходила длительное лабораторное испытание. В разработке «системы» и проведении ее в жизнь принимали горячее участие «старики» Художественного театра во главе с В. Немировичем-Данченко и многие ученики Станиславского среднего и младшего поколения.

Научная ценность труда Станиславского заключается в показывании объективных закономерностей художественного творчества. Так, например, искусство актера не может быть полноценным и выразительным, если актер не ставит перед собой манящей его идейно творческой цели, не располагает натренированным телом, поставленным голосом и т. п. «Система» не только указывает на эти обязательные условия сценического творчества, называемые Станиславским «элементами», но и предлагает определенные, проверенные на практике пути и приемы их развития и усовершенствования.

В «системе» Станиславского рассматриваются различные элементы духовной и физической природы артиста, а также их взаимосвязь и взаимодействие в процессе практической художественной деятельности. В ней изучается и самая последовательность творческого процесса, который протекает по определенным законам природы, включает в себя непременные стадии анализа и синтеза, восприятия и познания творческого материала, его художественной переработки, переживания и воплощения сценического образа $[2,1]$.

Для великого актера М. Чехова, ученика Станиславского, воображение и внимание, их совместная работа - первый способ репетирования. Более того, он считал, что образы, созданные воображением, живут самостоятельной жизнью. «Они (образы) вступают во взаимоотношения друг с другом, разыгрывают перед вами сцены, вы следите за новыми для вас событиями, вас захватывают странные, неожиданные настроения. Образы вовлекают вас в события их жизни, и вы уже активно начинаете принимать участие в их борьбе, дружбе, любви, счастье или несчастье. Вы с волнением следите за этими откуда-то пришедшими, самостоятельной жизнью живущими образами, и целая гамма чувств пробуждается в вашей душе. Вы сами «становитесь одним из них»» [6, 348].

Хорошо развитое воображение актера, его богатая фантазия увлекают его во внутреннюю и внешнюю жизнь образа. Увлеченный своим воображением, актер получит подсказку не только, касающуюся 
характера персонажа, его задачи и цели, но его отношения с другими действующими лицами, его взаимосвязь и взаимодействия. А в самом конце этого процесса актер поймет и в чем главная идея пьесы, ее квинтэссенция. Для того чтобы удержать перед своим внутренним «Я» нужный актеру образ, ему необходимо обладать достаточной силой своего внимания.

Внимание - это один из главнейших актерских элементов, т. е. элемент актерской техники. Практически все люди обладают вниманием и умением его сосредоточивать на каких-то действиях, но природа внимания актера совсем иная. Об ее особенности очень точно написал М. Чехов: «Что переживает душа в момент сосредоточения? Если вам случалось наблюдать себя в такие периоды вашей жизни, когда вы в течение дней и недель с нетерпением ждали наступления важного для вас события или встречи с человеком желанным и любимым, вы могли заметить, что наряду с вашей обыденной жизнью вы вели еще и другую - внутренне деятельную и напряженную, что бы вы ни делали, куда бы вы ни шли, о чем бы не говорили - вы непрестанно представляли себе ожидаемое событие. Даже и тогда, когда сознание ваше отвлекалось заботами повседневной жизни, вы в глубине души не прерывали с ним связь. Внутренне вы были в непрестанном деятельном состоянии. Эта деятельность и есть внимание. В процессе внимания вы внутренне совершаете одновременно четыре действия. Во-первых, вы держите незримо объект вашего внимания, во-вторых, вы притягиваете его к себе. В-третьих, сами устремляетесь к нему. В-четвертых, вы проникаете в него. Все четыре действия, составляющие процесс внимания, совершаются одновременно и представляют большую душевную силу» [6, 351].

Для внимательного актера в роли и на сцене нет мелочей, он всегда с большим интересом относится ко всему, что и как он делает сам, и к тому, что делают окружающие его люди, а если актеру интересно - то и зрителю будет интересно следить за актером на сцене, и таким образом актер обязательно «заразит» зрителя своими действиями.

Элементы внимания и воображения относятся к процессу работы актера над ролью, и к процессу работы актера над собой. Во время подготовки роли внимание и воображение играют ключевую роль, так как будят в актере эмоциональную память, возбуждают нервы артиста, приводят в действие его психофизический аппарат. Чем глубже внимание, тем сильнее погружение актера в образ, его проживание и, соответственно, воздействие на зрителя. 
Найти логику физических действий в роли (под физическими действиями подразумеваются психофизические действия) - непременное условие для успешной подготовки роли.

Не ответив на вопрос «Чего я хочу в каждой сцене и во всей пьесе?», актер не поймет, что он должен играть и как ему надо действовать. Слово «драма» по-гречески означает действие, т. е. без действия на сцене не происходит ничего. Разбивая пьесу на части, разделяя по сценам, актер ищет, прежде всего, свою действенную задачу, а также действенную задачу партнеров. Постепенно выявляя действенные задачи каждой сцены, он поймет и «сверхзадачу» всего спектакля и свою собственную. Он как бы охватит всю целостность произведения и замысла автора.

Из точного знания своих сценических действий в каждом эпизоде он выявит и «сквозное» действие во всей пьесе, т. е. главную цель и задачу его персонажа. Актер пишет партитуру своих физических действий. Только после этой проделанной работы, когда он точно знает, что ему надо делать в том или ином эпизоде, он может выходить на первую сценическую репетицию.

Не менее важно и оправдание найденных сценических задач, т. е. каков внутренний мотив или побуждение заставляют данный персонаж действовать так, а не иначе. Углубившись в авторский замысел, актер, включая свое воображение, интуицию и фантазию, добьется оправдания любой сценической задачи, малой или большой, найдет мотивацию любого поступка своего героя. Кстати, хороший актер найдет и подтекст или второй план роли, весьма нужный для придания своему персонажу многогранности, глубины душевных переживаний.

По выражению В. Немировича-Данченко, надо отыскать «зерно» роли. «То состояние, в котором находится действующее лицо, и есть его «зерно» - характер, с которым он родился, влияние на него среды, в которой врашается, влияние данных ближайших обстоятельств - все это суть условия, определяющие его зерно» [6, 224].

Актер включает все свое воображение, достает из своего жизненного опыта, интуиции, памяти, психики необходимые ему эмоции, чувства. Актер с особым вниманием наблюдает окружающих его людей, вновь и вновь прокручивает обстоятельства жизни своего героя как «киноленту», словом, «вживается» в роль.

В. Немирович-Данченко подчеркивал: «Заражать весь зал вы можете только своими нервами, своим темпераментом, причем здесь, конечно, очень многое зависит от того, насколько вы талантливы... Если психо- 
логически разбирать, то получается так, что актер, в зависимости от задач, какие он ставит перед собой, посылает мысль тем нервам, которые ему необходимы. Так мгновенно, что и не уловишь. И если он обладает сценическим талантом, то эти нервы вибрируют и быстро заражают.

Я все время употребляю слово «заразительно», потому что всякий талант - и писательский и актерский - заключается именно в способности заражать других людей своими (пока будем их так называть) «переживаниями». Это и есть талант, помимо «данных» - сценических и несценических» [4, 155-156].

Очень важным качеством, которое помогает отыскать «зерно» героя, является интуиция.

«При создании сценического образа интуиция занимает самое первое и важное место. Верно угадать и схватить интуицией данный образ - значит совершить большую и труднейшую часть работы.

Что значит «интуиция угадывает данный образ»? Это значит, что из суммы накопленных Духом впечатлений бессознательно угадываются миллионы, миллиарды тончайших движений души - природа всякого чувства, его ритм» [4, 150-151].

Если актер найдет верное внутреннее состояние своего героя, то он найдет и верное решение внешнего образа. Внешний образ в идеале всегда должен отталкиваться от внутреннего состояния.

Актер ищет наиболее выразительные формы внешнего образа, отталкиваясь от психологии персонажа, т. е. ищет характерность. «Нет нехарактерных ролей, как нет двух внешне и внутренне одинаковых людей. То, что различает их друг от друга, есть, говоря актерским языком, их характерность, как бы слабо ни была она выражена. Тот, кто неизменно изображает на сцене только самого себя, едва ли знает, какую творческую радость дает актеру перевоплощение, то есть принятие на себя характерных особенностей другого лица...» [6, 411-412].

Еще один важный элемент, найденный К. Станиславским, - темпоритм, который присутствует в каждой сцене и в каждом спектакле в целом», кроме того, каждый персонаж обнаруживает собственное качество темпоритма.

Темпоритм роли рождается от внутреннего состояния героя, от его действенной линии и сценических задач, хотя возможно и обратное воздействие, когда изменение внешних условий, порядка действия меняет его темпоритмические показатели.

Актеру важно найти не только общий внешний и внутренний темпоритм персонажа, но и определить внутренний ритм, темпоральную 
идею каждой сцены. Как писала К. Антарова, «в каждой роли столько ритмов, сколько их подсказало живое переживание. Ритм идет от чувства, которое зафиксировать нельзя. Но самый ритм - как пульс переживания - зафиксировать можно. Его можно установить раз и навсегда. Он создает ту почву, на которой легко возрождается переживание актера при повторении роли. В опере актер берет разные ритмы и темпы композитора. Поэтому я всегда говорю, что оперные артисты счастливее нас, драматических. У них готовы ритм и тепм. Артист драмы - сам творец ритмов. Он должен их почувствовать, угадать, создать и влиться в общее коллективное творчество спектакля, не нарушив его гармонии» [1, 88-89].

Хочется упомянуть здесь и о значении паузы. Все слышали выражение «мхатовская» пауза, держать паузу, жить в паузе. Пауза - сильнейшее средство выразительности ибо, не останавливая ни на минуту сценическое действие, она дает и зрителю и артисту слиться в полнейшей тишине в единое целое, почувствовать взаимное дыхание. В паузе актер может выразить то, что он не доиграл в тексте, или то, чего вообще в тексте нет, или то, что следует за текстом. Например, в чеховских пьесах в репликах героев очень много троеточий, слова как будто ничего не значат, а между ними три точки, и вот эти три точки короткие и длинные паузы, несут смысловую и действенную нагрузку.

«Пауза является предельной формой внутреннего действия, когда внешние средства выразительности исчезают и сила излучения (актера) возрастает. Пауза может быть полной и неполной. В последнем случае внешнее действие на сцене не прекращается, но происходит «под сурдинку», имея лишь большую или меньшую тенденцию стать паузой. На зрителя такая пауза производит тот же эффект, что и полная: он чувствует ее настораживающую будящую внимание силу...

Существуют два рода пауз: предшествующие действию и следующие за ним. Паузы первого рода подготавливают зрителя к восприятию предстоящего действия. Они пробуждают внимание зрителя и благодаря излучениям (а часто и атмосфере) подсказывают ему, как он должен пережить предстоящее сценическое событие. Второй род пауз - то, что следует за текстом, суммирует и углубляет для зрителя полученное им впечатление от действия, уже совершившегося. Поэтому действие, не сопровождающееся паузой (полной или неполной), оставляет в зрителе лишь поверхностное впечатление» [6, 418-419].

В паузе исполнитель живет внутренним монологом, внутренними видениями, конкретной сценической задачей, только в этом случае 
он заполнит ее содержанием, сумеет удержать образные нити спектакля и внимание зрительного зала. И, конечно, темпоритм его персонажа обогатится тысячекратно, образ приобретет глубину и выпуклость.

Работая над ролью, актер как бы «склеивает» в единое целое те элементы, о которых было уже рассказано, но для того, чтобы роль приобрела законченную форму, актеру требуется все это соединить в слове.

«Слово становится венцом творчества, оно же должно быть и источником всех задач - и психологических, и пластических. Если оно с самого начала неверно понято, неглубоко психологически, неметко в определении характерности, или эпохи, или быта, или стиля автоpa, актерская мысль пойдет по неверному пути и приведет где-то на протяжении роли к художественной трещине, к разрыву с течением пьесы... Вот тут то и ищите наши грехи. Все задачи актера только тогда дойдут до зала, когда выльются в великолепно, старательно, с талантом написанной фразе. Фраза - это и есть самое главное по содержанию. Содержание этой фразы - источник всех ваших переживаний, тончайший смысл этой фразы - стимул для посыла нервам известной мысли. И все это возвращено во фразу» $[4,166]$.

В слове фокусируется и физическое действие и результат воображения артиста, его чувства, порывы, в интонации заключена вся гамма внутреннего состояния персонажа. По выражению Станиславского, «слово - отзвук состояния духа». Поэтому произнести слово актер должен иметь право, в творческом понимании, конечно. За словами должен стоять образ, созданный воображением артиста, его переживания, его мысли. Артисту, после его длительного и глубокого изучения и анализа пьесы, «после вживания» в свою роль, становится ясна без слов вся драма. Но для зрителя драма должна быть пояснена словами, и в самом конце творческого процесса работы актера над ролью он приступает к изучению текста роли. В этом случае актер избежит пустого произнесения текста, раскрашивания голосом слов роли, иллюстрирования диалогов.

Сценическое действие - это центр оперного спектакля. В. Немирович-Данченко подчеркивал: «Композитор приносит нам не симфонию, а музыкальное произведение для театра» [3, 258-259].

Оперная драматургия предусматривает те же слагаемые, как и любая театральная пьеса: конфликт, сюжет, завязка, развязка, кульминация и т. д. Не случайно многие оперные произведения в своей 
сюжетной основе опираются на литературно-драматические композиции, а данные композиции входят в память культуры в ином музыкально-сценическом качестве и часто глубже «запоминаются» именно в данной трансформации (достаточно вспомнить «Бориса Годунова», «Евгения Онегина», «Пиковую даму», «Каменного гостя», «Моцарта и Сальери», «Сказку о царе Салтане» А. Пушкина, «Демона» М. Лермонтова, «Фауста» и «Вертера» И. Гете, «Свадьбу Фигаро» и «Севильского Цирюльника» П. Бомарше, «Отелло» и «Фальстафа» В. Шекспира, «Дон Карлоса» Ф. Шиллера и многие другие. Настоящая литература вдохновляла композиторов насыщенным действием, глубиной и силой характеров, великими идеями и поступками).

Но, несмотря даже на самую лучшую литературную основу, опера - это замысел композитора, потому что он рассказал нам драму музыкальными средствами. Именно созданная им музыкальная драматургия будет задавать основной тон в оперном театре. В музыке уже есть «зерно спектакля», все психологические ходы, все характеристики персонажей, их взаимодействия, конфликт, действенная линия, атмосфера происходящего, темп и ритм действия и т. д.

Опера - жанр синтетический еще и потому, что здесь должны гармонично соединяться между собой в единое целое несколько исполнительских искусств - вокальное, художественно-сценографическое, оркестровое, хоровое, танцевальное, наконец, режиссерское, В этом заключается сложность исполнительской формы данного жанра, но это является и причиной значительности, и социальной встребованности оперного воздействия.

«Нужно ли спорить о том, что в опере в подавляющем большинстве случаев преобладает музыка, композитор, а потому чаще всего она именно и должна давать указания и направлять творчество режиссера. Это, конечно, не означает, что музыкальная сторона спектакля, во главе с дирижером, должна задавить сценическую часть во главе с ее руководителем - режиссером. Это означает, что последняя часть, то есть сценическая часть, должна равняться по музыкальной, помогать ей, стараться передавать в пластической форме ту жизнь человеческого духа, о которой говорят звуки музыки, объяснить их сценической игрой. Поэтому ошибаются те певцы, которые во время интродукции к арии прочищают себе нос или горло для предстоящего пения, вместо того, чтобы переживать и выявлять то, что говорит музыка. С первого звука вступления они вместе с оркестром уже участвуют в коллективном творчестве оперы» [5, с 404]. 
Этим словам Станиславского почти сто лет, но актуальность их очевидна. Главный ориентир в оперном театре - музыкальная драматургия произведения, созданная композитором. Партитура оперы жизнь «человеческого духа»; композитор выразил ее в музыкальных звуках инструментов оркестра, вокальной линии главных, второстепенных персонажей и хора, в темпах, ритмическом рисунке, паузах, тональностях и т. д. Поэтому изучение и анализ партитуры - обязательное и необходимое условие для всего творческого ансамбля, создающего оперный спектакль. После анализа и тщательного изучения партитуры и либретто каждый участник спектакля должен знать свою «сверхзадачу», свою действенную линию, сквозное действие, полную картину логики сценических действий.

Научная новизна статьи состоит в развитии и расширении психологического подхода к оперной вокально-интонационной интерпретации как к артистической музыкально-театральной деятельности, в углублении со стороны опероведения представления о психологическом театре как особом художественно-творческом феномене.

Выводы работы позволяют определять основные интерпретативные задачи режиссера, дирижера и певца-артиста, организующих оперную постановку, обнаруживать их специфику и художественносмысловое единство. Так, основная задача режиссера оперной постановки - выявить главную идею автора и найти «зерно» всего спектакля. В работе с певцами-артистами он должен помочь им раскрыть характер их персонажей, психологию, логику поступков, нащупать действенную линию, выстроить точное сценическое общение, найти «зерно» роли.

Основная задача дирижера оперной постановки - найти музыкальное «зерно» спектакля, действенную линию в музыке, определить ритмические, темповые и тембральные нюансы каждого музыкального фрагмента оперы, добиться такого звучания солистов, хора и оркестра, которое полностью соответствует характеру исполняемой сцены.

Основная задача певца-артиста оперной постановки - найти верные музыкально-вокальные и сценические средства в своей художественной палитре, которые позволили бы ему полностью перевоплотиться в создаваемый им персонаж, выразить ту идею автора, ради которой создавался этот персонаж, интонационно высвободить и представить заключенный в его образе смысл. 


\title{
СПИСОК ЛИТЕРАТУРЫ
}

1. Антарова К. Театр - мое сердце. М.: «Сиринъ садхана», 2004. 320 с.

2. Кристи Г. Книга Станиславского «Работа актера над собой». URL: http://biblioteka.teatr. - obraz.ru/kode/7247.

3. Марков П. Режиссура Вл. И. Немировича-Данченко в музыкальном театре. М.: ВТО, 1960. $411 \mathrm{c.}$

4. Немирович-Данченко В. О творчестве актера: хрестоматия. Учеб. пособие для выш. и сред. учеб. заведений. 2-е изд., доп. М.: Искусство, 1984. 623 с.

5. Станиславский К. Моя жизнь в искусстве. М.: Искусство, 1980. 430 с.

6. Чехов М. Путь актера (Мемуары). М.: Транзиткнига, 2003. 554 с.

\section{REFERENCES}

1. Antharova, K. (2004). The theater is my heart. M.: «Sirin sadhana» [in Russian].

2. Kristi, G. Stanislavsky's book «The Work of an Actor Over Self». URL: http:// biblioteka.teatr.-obraz.ru/kode/7247 [in Russian]..

3. Markov, P. (1960). Directing Vl. I. Nemirovich-Danchenko in the musical theater. Moscow: WTO [in Russian].

4. Nemirovich-Danchenko, V. (1984). About the actor's work: Reader. Textbook. allowance for hight. and media. training. institutions; 2 nd ed., Ext. Moscow: Art [in Russian].

5. Stanislavsky, K. (1980). My life in art. - Moscow: Art [in Russian].

6. Chekhov, M. (2003). The Way of the Actor (Memoirs). Moscow: Transitkniga [in Russian].

Стаття надійшла до редакції 15.06.2016

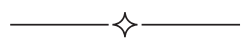

УДК 78.01/.071.1+784.3

\author{
Ду Чжоу, \\ соискатель кафедры теории музыки и композиции \\ ОНМА им. А. В. Неждановой \\ odma_n@ukr.net

\section{ЛИРИЧЕСКОЕ КАК СЕМАНТИЧЕСКАЯ ДОМИНАНТА КАМЕРНО-ВОКАЛЬНОГО ТВОРЧЕСТВА}

Цель статьи состоит в освещении природы лирического как эстетического модуса, художественной сферы и психологической установки, в определении специфики проявления лирического в музыке, композиционных и стилистических показателей лирической музыкальной семан- 